\title{
أثر السيد تاج الدين الآوي في الحياة السياسية والادارية

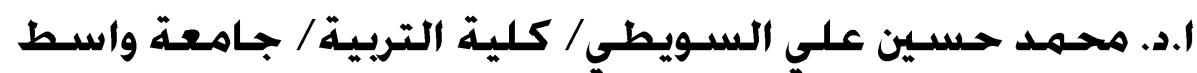

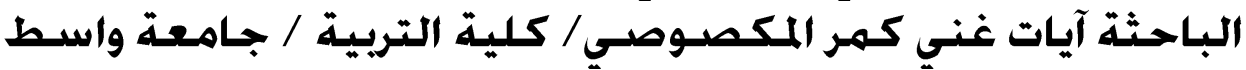 \\ المخلاصنة:
}

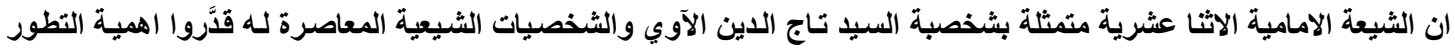

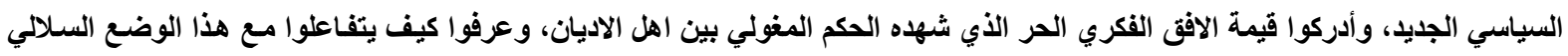

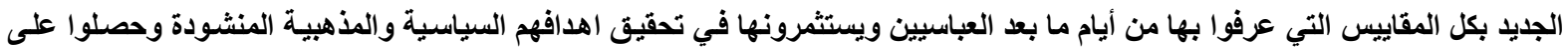

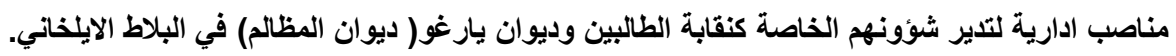

The impact of Mr. Tajeddin Al-Awe In political and administrative life

Prof. Dr. Mohamed Hussein Ali Al-Swaiti

Ayat Ghani Kammer Al- ksousi

The Twelfth Imam Shi'ites represented by Mr. Taj al-Din Al-Awei and the contemporary Shiites, who appreciated the importance of the new political development, realized the value of the free intellectual horizons witnessed by the Mughal rule among the people of the faiths and knew how to react to this new religious situation by all the standards they knew from some days After the Abbasids and invest them in achieving their political and sectarian goals desired and obtained administrative positions to manage their own affairs as the Student Union and Diwan Yargo (Diwan Grievances) in the court of Elijani.

\section{| المقدمة:}

ان الوضـع السياسـي الجديـد الــي شـهـه النصـف الثـاني مـن القـرن (السـابع الهجـري / الثالـث عثـر

الميلادي) و الذي نجم عنه تصفية الخلافة العباسية والبيت العباسي العدو التقليدي للأماميـة الاثتـا عثـرية خاصـة و الثيعة عامة، كان قد فتح لققهاء الامامية تجربة جديدة لم تكن قد اتيحت لهم سـابقا، بفضل الواقع الجديد لبغداد أيام الايلخانيين ، الامر الذي انعكس على اعمال كبـار رجالات الاماميـة في خوض غمـار السياسـة لدى الحكام الجدد، بعدما ابتعدوا عنها أيام الدولة العباسية، وابرز مثال على ذللك السيد تاج الدين الآوي الذي تسلم مناصسب عديدة فضلا عن الدور الاستشاري الذي قام به ايام السلطان غاز ان والجايتو

\section{أوغأ- أنرهه في المهياة السياسية:}

كان للسيد تاج الدين لما يمتلكه من مؤهلات علمية وثقافية وحنكة سباسية مساهمات واضحة في الحياة السياسـية، وهـو مــا استشـفيناه مـن الروايـات الـو اردة عنـه في المصـادر المتـو افرة بـين أيـدينا. وبـرزت تلكـك

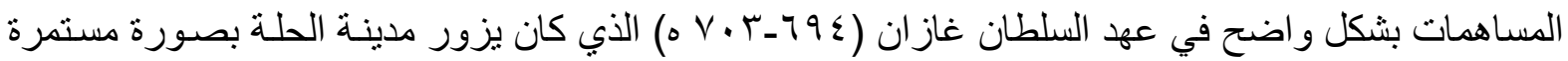
،ويلتقي بعلمائها، ومنهم السيد تاج الدين، لغرض مشاورتهم في الأمور العامة ومنها الاحداث السياسية(').

و أشـار المؤرخ (وصساف) إلى ان السـطان غـاز ان لمـا كان خـارج العاصـمة الايلخانيـة ولعله في مقره الثتوي أصابه مرض فتو افد عليه الأطباء هنالك في محاولة لعلاجه لكن دون جدوى، فطلب نقله إلى مقره الدائم في مدينـة تبريـز، وفي هذه الأثتـاء زادت علتهه وتفـاقم مرضـه وصـارت "قوتـه تتسـاقط كتسـاقط الاوراق مـن الأشجار وظهرت عليه امار ات الموت وضعف مز اجه..."(r)، فأرسل في لحظات حياته الأخيرة تلك الى كبار رجال الدولة من القادة والعلماء والوجهاء للقاء بهم وكان من ضـمن هؤلاء العلمـاء السبد تـاج الدين كمـا صـرح 
بذللك وصاف بقوله " امر بحضور الامر اء المغول و القادة والحكماء والوزر اءو التابعين فحضر عنده كل من امر اء قبائل باغولدار وجيتو وطو غاي وكذلك حضر قتلغ يوقا وطرمطاز و المشيرين و الخو اجين المعظمين رشيد الدين وسعد الدين ساوجي و الاوجي......" (־) والاوجي كما عرفنا هو لقب السيد تاج الدين(ع). ومع ان المؤرخ (وصاف) لم يبين لنا سبب دعوة السلطان غاز ان قبيل وفاتـه لكبار رجال الدولة ومنهم السيد تاج الدين، الا أن سبب ذلك وبلا أدنى شك كان للتشاور بشأن الدولة ومستقبلها السياسي بعد وفاة السلطان. ومما تقدم يظهر ان لعلماء الثيعة عامة و على وجه الخصوص منهم السيد تاح الدين مسـاهمات و اضحة في الثأن السياسي في عهد السلطان غازان، اذ كان السلطان بستشير هم في بعض الأحداث السياسية ويقصدهم في بعض الأحيان الى مقر وجودهم الرئيس في مدينة الحلة لأجل ذللك.

ويبدو إن علماء الثيعة قد احرزوا مكاسب أكثر من غير هم في هذه المرحلة من عمر دولة مغول فارس

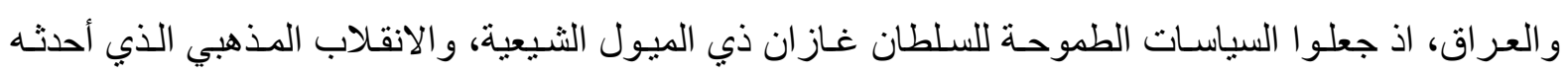

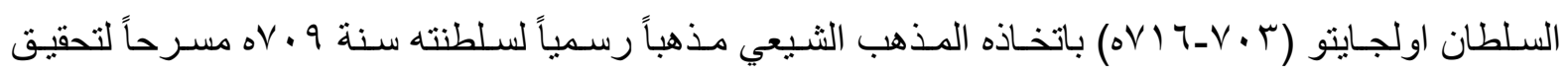
أهدافهم السياسية(0).

ففي الوقت الذي أدرك فيـه المغـول أهميـة الثـيعة و علمـائهم بصفتهم عنصـر تـوازن مـع أهل السـنة، و عنصر اً يطمأن اليه في عدم المنافسة على العرش في الداخل، وذريعـة لضرب اعدائهم المماليك ومن يتبعهم

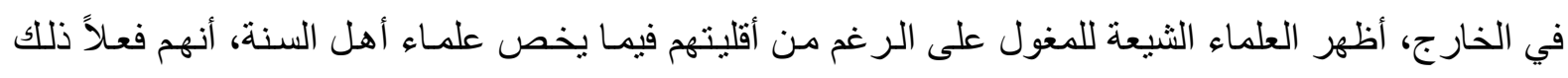
العنصر الذي يلائم تطلعات المغول الايلخانيين السياسية، وهذا مـا يتضح من ميل السلطان غاز ان الى الثيعة ولقاءاته المستمرة مع علمائهم في مدينتي الحلة وآوه(؟). وبالمقابل وجد علماء الثيعة في المغول وسيلة لتحقيق مصالحهم السياسية وأهدافهم العقائديـة، لذا كانت

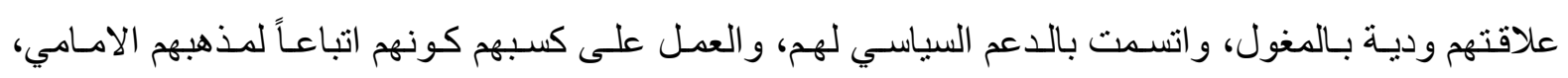
و استثمار كل ذلك في تحقيق أهدافهم المثالية في الحكم بمنهج أئمة أهل البيت (عليهم السلام). وقد شكل كل ذلك تطور اً سياسياً واضحاً في تاريخ الثيعة في هذه المرحلة من عمر دولـة مغول فـارس

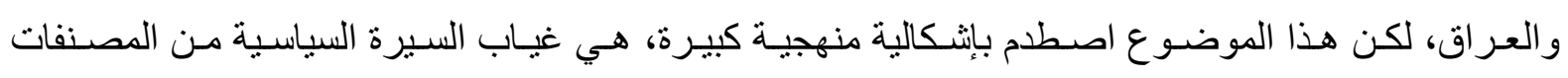
التاريخية سو اء أكانت الثيعية منها أم السنية لز عماء الثيعة و أبرز هم السيد تـاج الدين، ومـع ذلك تلمسنـا ملامـح

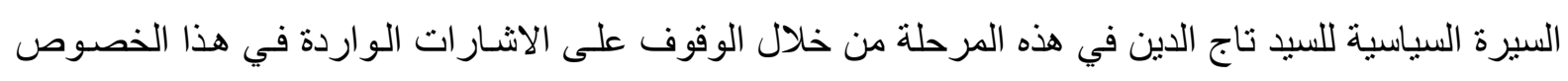
وربط بعضها بالبعض الاخر لأجل الوصول الى معلومة نافعة.

فقد كان هناك تعاون سياسي بين الزعيم الثيعي السيد تاج الدين و السلطان المغولي غاز ان، ونستشف هذا التعاون من اللقاءات التي حصلت عند زيارة السلطان غاز ان لمدينة الحلة سنة (r • Vه)، ثم لمدينة أوه سنة

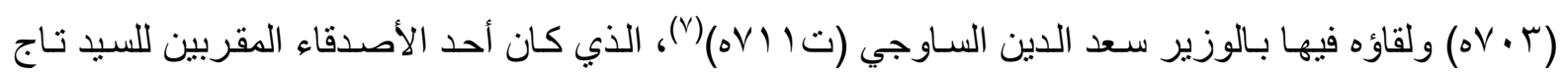
الدين، فحتماً جمع ذلك اللقاء السيد بالسلطان، والا لماذا هذه الزيار ات الخاصـة لهذه المدن؟؟ و وأيد ذلك ان العـالم 


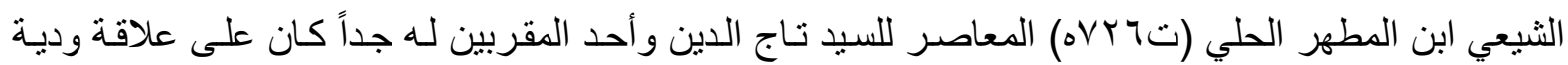

بالسلطان غاز ان، ولم يكن يحصل ذلك لو لا دعم زعماء الثيعة للمغول و التعاون معهم (^).

أما على صعيد السياسـة الخارجيـة لاسيما في شـأن الحرب مـع المماليك، فلم يتجـاوز السلطان غـاز ان الاستشارة السياسية للعلماء الثيعة، ومن المرجح إن السيد تاج الدين في طليعة هؤلاء العلمـاء، و هو مـا أكدته

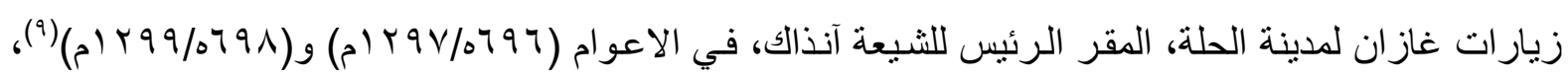

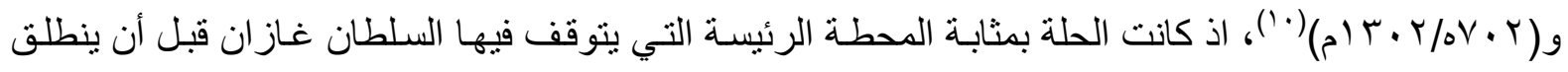
بحملاته العسكرية على بلاد الثنام لمقار عة عدوه اللدود المماليك.

و السؤال هنا لماذا مدينة الحلة من دون غير ها من مدن العر اق ونعتقد ان الجواب يكمن في أن السلطان

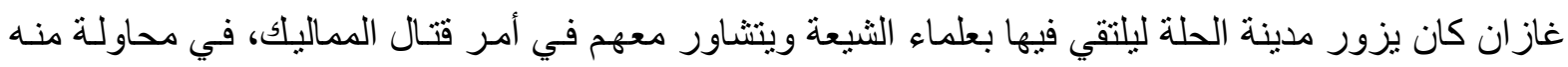
لإضفاء الثر عية في حربه فضلاً عن توسعت قاعدة التأييد وكسب الر أي العام.

ولم تقتصر المساهمات السياسية للسيد تاج الدين في عهد السلطان غاز ان فحسب، انما استمرت في عهد

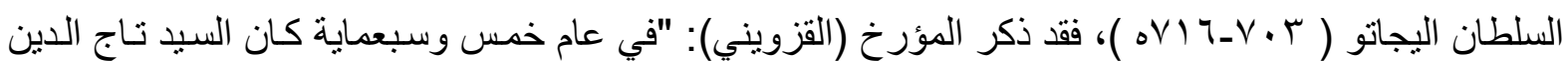
كور سرخي نائبا للأمير هورقداد ثم صار نائباً للأمير سونج ثم صسار معلماً للسلطان ثم صسار كاتبـا لديه فصسار يحالف الوزراء والامراء"(').

ثم ذكر ان السلطان اليجايتو أمر بإعدام السيد تاج الدين، ولم يعط سبيا لإعدامه، وهذه الروايـة انفرد بها (القزويني) من بين المؤرخين الفرس والعرب، ولم يظهر أي أثر سياسي للسيد تـاج الدين في المدةاللاحقة بين بين

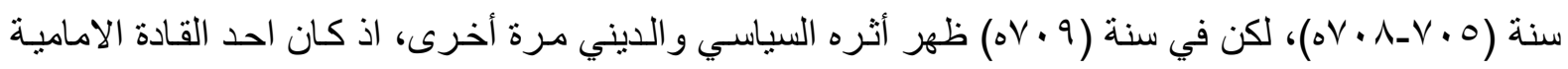
الذين حرضوا السلطان اولجايتو على تبني المذهب الثيعي، وتمكن من تحقيق إنجازاً في هذا المجال كان مثنار

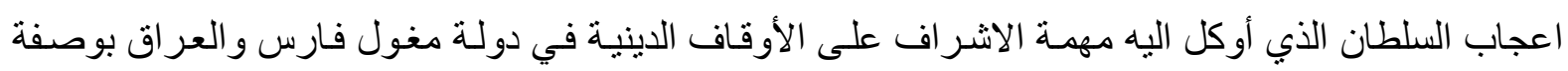
نقيب نقباء الممالك(r')، وتأثيره السياسي كان كبيراً عند نوليه هذا المنصب، و وعلى الرغم من اغفال المصنفات

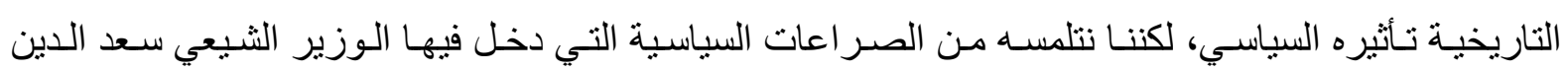
الساوجي الذي ربطته علاقة حميمة مع تـاج الدين مـع الوزير رشيد الدين فضل الله الثـافعي حين أراد الوزير الثيعي ان يعيد اللعبة السياسية نفسها التي لعبها رشيد الدين فضل الله عندما أراد ان يزيل عن بـلاط السلطان

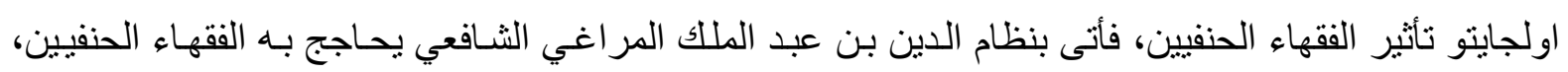
فنجح وكان نجاحه تمهيداً للتشيع الامامي الذي حاول به الوزير المنافس سعد الدين الساوجي كسر شوكة رشيد الدين فضل الله، فأتى بالفقيه تاج الدين الاوي الذي قطع الحجج على نظام الدين، وبجهوده وجهود الاخرين مثل العالم (ابن المطهر الحلي)، وبعدها اعلن التشيع مذهباً رسميا في دولة اولجايتو (rآ).

ومع تسيد المذهب الثيعي الامامي، نجحت المنـاورة التي اداهـا سعد الدين السـاوجي في دفع المذهب الثيعي نحو ان يكون المذهب الرسمي، لكنها لم تنجح في تحقيق مطامحه الشخصية في ابعـاد غريمه رشيد

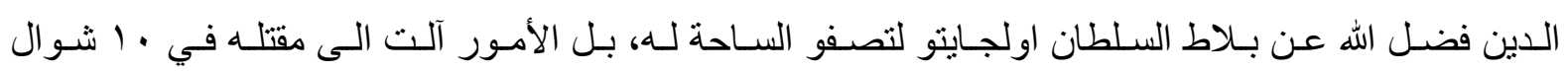




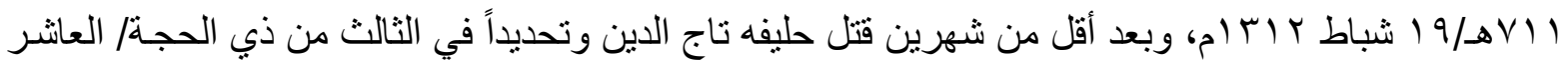

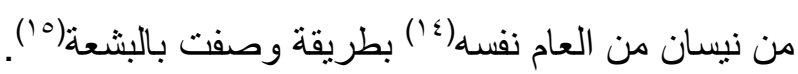

وفي نهاية حديثنا عن اسهامات السيد تـاج الدين في الحياة السياسية لابد من التتويـه الى ان السيد تـاج الدين كـان شخصية سياسية مؤثرة حيث يذكر (جعفريـان) إن السيد تـاج الدين كان من جملـة سياسـي البلاط

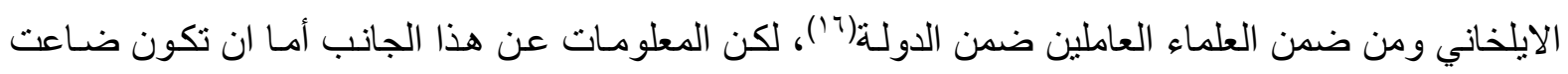
بفعل عو امل الزمن، أو غيبت عن عمد لأسباب طائفية وسياسية، بدليل وجود عنوان صريح في مخطوطة

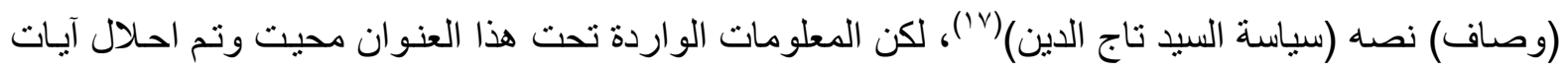
قر آنية محلها.

\section{ثانياً- أنُره في الحياة الادارية:}

تمتع السيد تاج الدين بخبرات علمية وسيرة طيبـة أهلته لأن يسند اليه وظليائف ومهمـات اداريـة عديدة، لعل أهمها:

ا - نقيب نقباء الطالبينين:

قدم (المساوردي) مفهوماً واضـحاً لنقابـة الأشـر اف وأهم واجباتهـا بقوله: "سمّو ها بـذلك إثـارة إلى أنها تتعلق بأثر اف المسلمين وهم أهل بيت النبي (صلى الله عليه وآلة)، وذللك أن عائلة النبي كانت في أو ائل الإسـلام محفوظة الحرمة لقرب عهدهم من النبوة، فكانو ا يجعلون على أهل بيت النبي (صلى الله عليه و آلـه) رئيساً منهم يتولى أمور هم، ويضبط أنسابهم، ويدوّن مو اليدهم ووفياتهم، وينز ههم عن المكاسب الدنيئة، ويمنعهم من ارتكاب

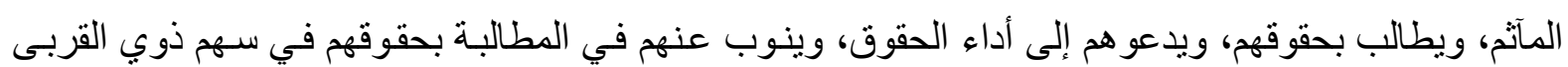

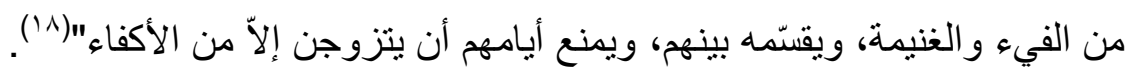

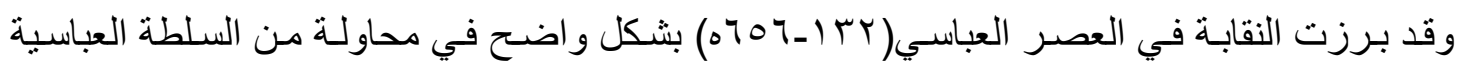
لاستمالة الثيعة وكسب الر أي العام، وخصص للنقيب ديوان خاص به يدعى ديوان النقابـة(9)، وفرضت فئس الدولة

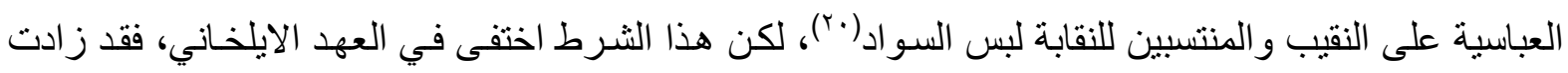
أهمية النقابة، وكان السيد تاج الدين يتمتع بحريـة فريدة من نوعها في منصبه بحكم احتر ام السلطان لله و عدم فرض لباس خاص عليه.

ان منصب نقيب نقباء الطالبيين هو اعلى منصب حتى انه اعلى من منصب نقيب نقباء الهاتشميين(r)، وينصب الشخص في هذا المنصب بأمر من الحاكم الرسمي للاولة حيث كان لديه منزلة خاصـة ومقربـا جدا من هن السلطان و لاسيما في المر اسيم الرسمية والاجتماع العام والخاص ويكون المسؤول عن الطالبيين إمـام السلطان، وكان اول من استلم منصب نقابـة الاشر اف من أجداد السيد تـاج الدين هو (ابو محمد الحسن بن علي بن ولن علي

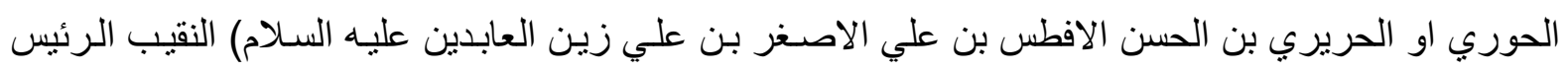

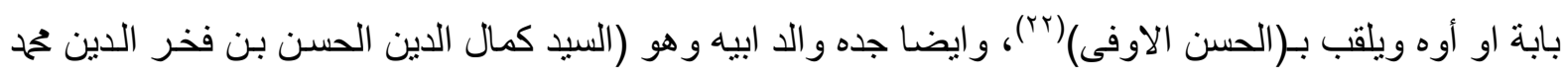


بن رضي الدين محمد بن زيد بن الداعي بن زيد بن علي بن الحسين بن ابي الحسن علي) ايضـا كان من نقباء أوه،

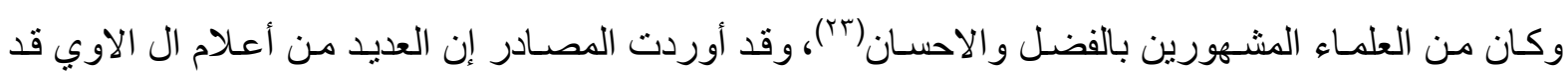

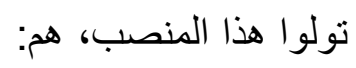

$$
\begin{aligned}
& \text { 1- رضي الدين ححمد بن محهد(؟) . } \\
& \text { r- تاج الدين ححم بن مجد الدين(ro(). }
\end{aligned}
$$

r- نظام الدين الحسين بن تاج الدين(זr).

ع - رضي الدين محمد بن شرف الدين(rV)

هـ شمس الدين الحسين بن رضي الدين(r^).

$$
\text { 7- جلال الدين علي بن شرف الدين(rq). }
$$

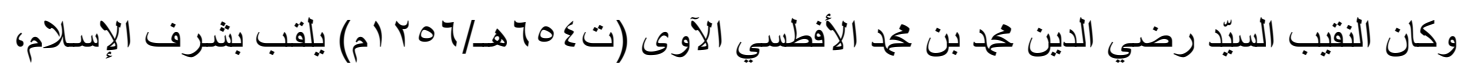

وتاج المسلمين، وملك السادات، ونقيب النقباء في العالمين(·•).

وكان بعض النقبـاء من أسـرة الآوى قد تولى القضـاء و الصدارة بـالبلاد الفر اتيـة، وتولّى بعضـهم نقابـة العلويين في النجف الأشرف و الحلّة وكربلاء و الكوفة، حتى إن اسرة الاوي ذكرت من ضمن الأسر التي تولت

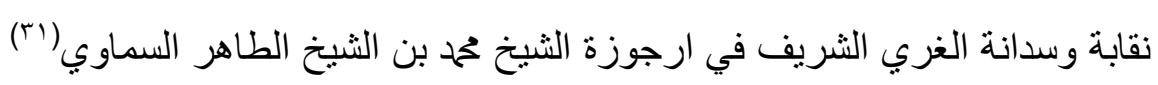
فكان النقيب يقوم بتولية امرة المرقد الثريف وتعيين السادن له في بعض الاحيان(r؟r). أما حوزة عمل النقيب التي يعمل فيها تكون رقعهه جغر افيـة محددة مثنل مدينة او اكثر، لكن السيد تـاج الدين عندما فوض إليه هذا المنصب جعله نقيباً لنقباء الممالك في العراق وايران، وتضم مدن الكوفة وتو ابعها

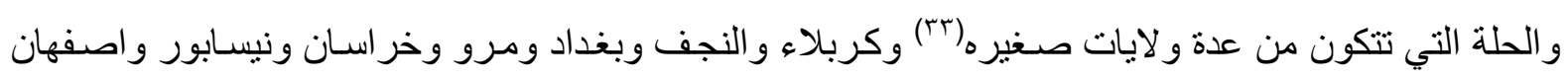

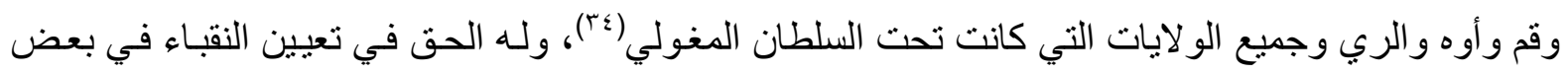

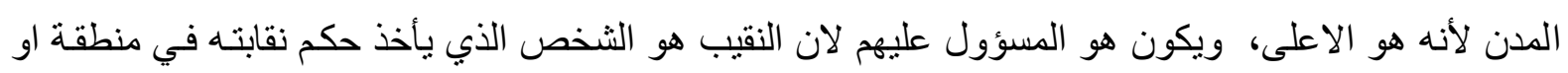

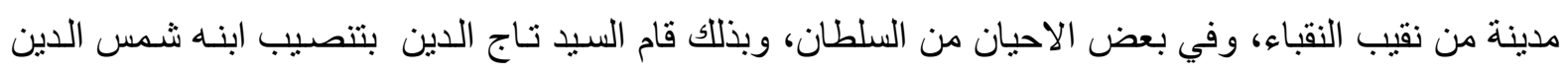
الاوي نقيبا على العر اق بعد إن كان النقبب السيد الفاضل قوام الدين احمد بن علي بن علي بن موسى بن جعفر

$$
\text { الحسني الذي و لاه السلطان الجايتو النقابة(ب). }
$$

وورد ذلك أيضاً عند (ابن بطوطة) بقوله: "ان النقيب في عهد دخولي إليها نظام الدين حسين بن تاج الدين الآوى نسبة إلى بلده آوه من عراق العجم أهلها رافضة وكان قبله جماعة يلي كل واحد منهم بعد صـاحبه منهم جلال الدين بن الفقيه ومنهم قوام الدين بن طاووس ومنهم ناصـر الدين بن مطهر بن الثـريف الصـالح

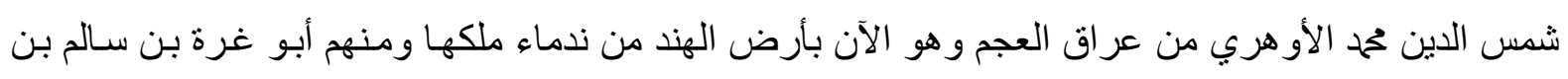

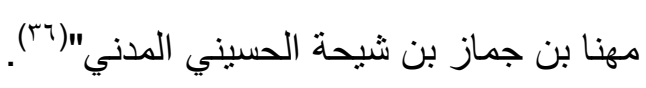


و النقيب صدر الدين حمزة بن الحسن بن حمحد بن حمزة بن الحسن اميركا بن علي بن حمح بن ابي الحسن

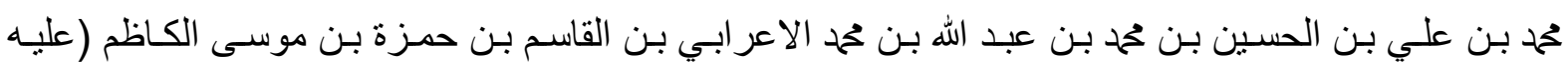
السلام)، وكـان نقيباً لطوس فضـلا عن انـه سيد جليل القدر، أطلق عليه لقب (الدفتر دار)، في عهد السلطان

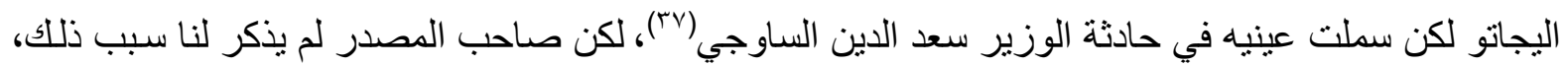
لكن من الواضح إن كل من كان قريبا من السيد تاج الدين وحتى النقباء الذين كانوا في عهده تم تصفيتهم بعد اطلاق التهم عليهم بحجة أنهم كانوا من المسـاعدين للاوجي في الفوضى التي حدثت التي اتهم بانـه يريد قتل السلطان اوليجاتو، لكن هذا الثيء قام بتدبيره الهذاني وممن تولى نقابة الطالبين في تلك المدة وبأمر من السيد

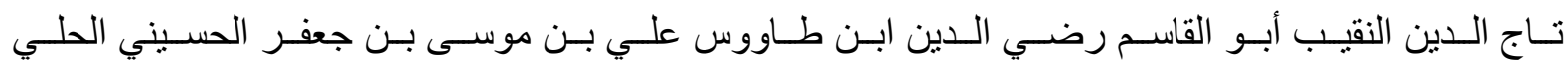

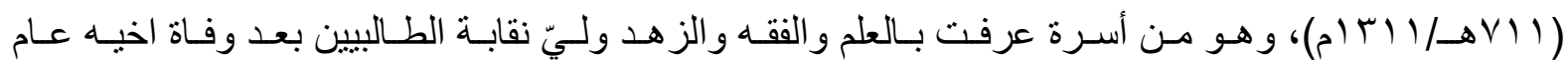

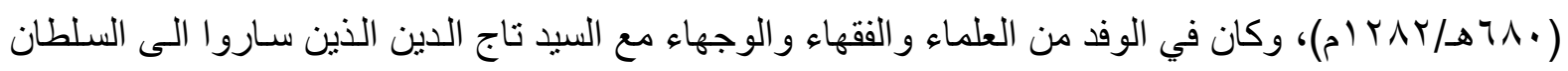

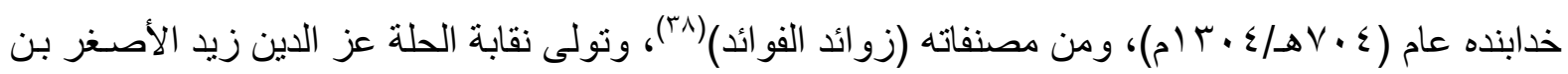

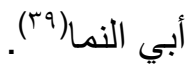

ويكون النقيب مسؤولاً عن مدينتين مثنل البصرة والكوفة او اكثر (·؛) او إن يكون النقيب مسؤو لا عن محلة واحدة فقط في مدينة كبيرة مثل الكرخ في مدينة بغداد، حيث كان هبـة الله بن علي الثـجري وكل هؤلاء النقباء يتم اختيار هم في بعض الاحيان من أهل تلك المدن (1). إما باقي المدن فلم ينصب عليها نقباء بحسب المصـادر التي اطلعنـا عليها، وبذللك كان السيد تـاج الدين هو المسؤول عن نقابتها وتحت ادارتـه، ويوجد ايضـا خليفة النقيب لان النقباء كان لديهم وظـائف قضـائية مثل الحسبة وكانو الصحاب هذا الاختيار حيث يقوم النقيب باختيار شخص فقيه عادل ومطاع بين الناس ليكون خليفة النقيب، وكان هذا المنصب معروف منذ العصر العباسي(r؟)، فكان من احكام وخصوصيات النقيب حقه في

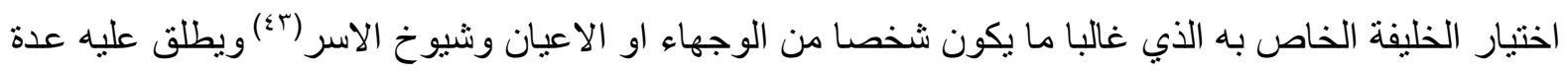

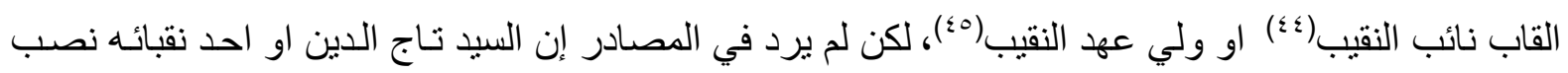
نائبا له.

وللنقيب ايضا وزير يدعى بوزير النقيب، واول من نصب به الحمزة بن ابي ححمد بن امبركا بن الحسن،

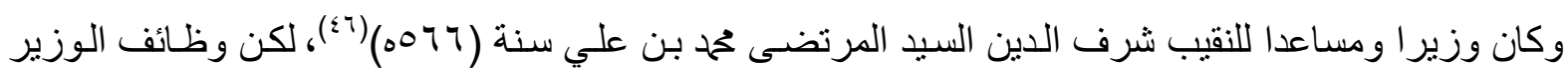
غير معروفة لدينا ولم يرد في العهد الايلخاني ولاسيما في عهد السيد تاج الدين هكذا منصب في ديوان النقابة. ومن ضـمن تتـكيلات ديوان النقابـة حاجب النقيب الذي يوضـع للنقبـاء الكبـار ولنقبـب النقبـاء بسبب الوظائف و المشاغل الخاصة المتعددة لهم لذا كان على الحاجب السبطرة على الدخول و الخروج على النقيب وتحديد ساعات عمله وتتظيم اشغاله وكانت تصدر الاوامر من ديوان النقابة إلى النقباء توصسي بـان على النقيب اتخاذ حاجب او اكثر (\&v). 
ومن ضمن الاوامر الاخرى التي يصدر ها نقيب النقباء هو إن يضع النقيب خازنا له او صاحب الخزينـة لان وجوده ضروري إلى جوار النقيب من اجل الحماية وتثبيت الاموال في الديوان و ايضا هناك امر من ديوان النقابة إلى النقيب بتعيين وكيل للنقيب من اجل تسهيل امور السـادات(^ء)، إمـا وصـي النقيب فكان يعينـه النقيب قبل موته ويكون وصيا على الاعمال الديو انية والمالية واحيانا يكون من المقربين له مثل او لاده كما كان رضي لهي

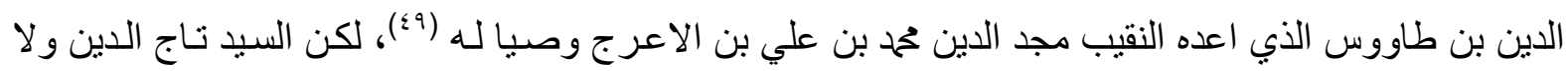
ابنه النقيب شمس الدين تم وضع اوصياء من بعدهم بسبب الظلم الذي وقع عليهم وحتى على حفيده الذي كان صغير الم يحصل على هذا المنصب و تم مطاردته ولكن اصبح نقيبا فيما بعد أما شريك فو هو من عناصر ديوان النقابة اي إن يكون هناك شريك للنقيب في منصبه(·) وايضـا خادم النقبب وهو من الاشخاص المقربين للنقيب(1) وايضا عامل النقابة وهي كلمة تطلق على كل العـاملين في ديوان

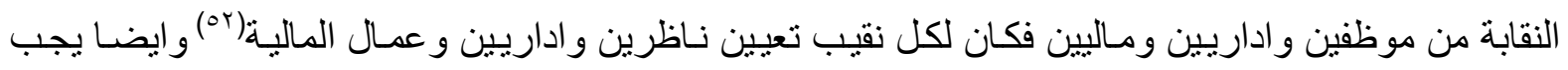

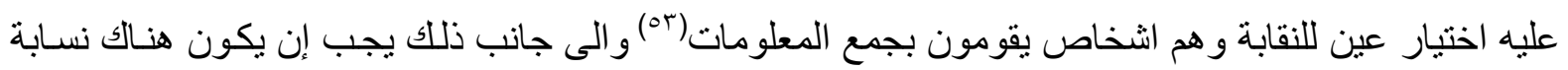

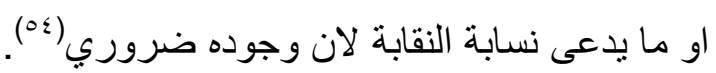

وورد في بعض المصادر بعد إن يتم تتصيب نقيب النقباء في بغداد يعطى له دار فيكون مقر النقابته(00)

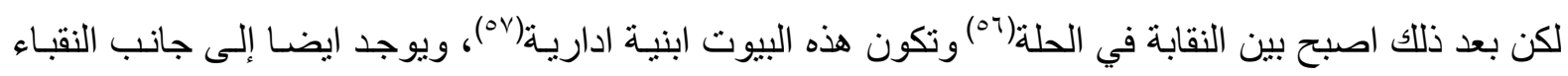
الكتاب او مـا يدعى كاتب النقيب الذي يقوم بحفظ السـلات ودفاتر الحسـابات وسجلات الاوقـاف و الامـلاك ومستغلات الطالبيين بحفظها وتنسيقها (1)، وكان يوجد عند كل نقيب كتب خاصـة بالأنساب وتـدعى جريدة

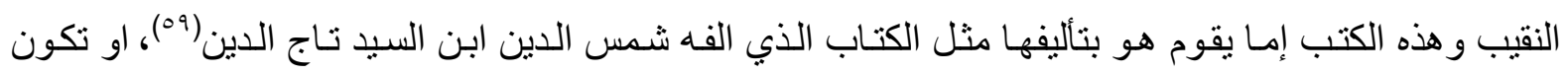
محفوظه عنده ويحصل عليها النقيب عن طريق تقريب النسابين إليه ويطلب منهم تأليف هذه الكتب فكانت على شكل اشجار توضح نسب اسرة معينة او بشكل مبسوط اسم الاجداد والاباء والابناء مع ذكر الاسم والنسب لكل

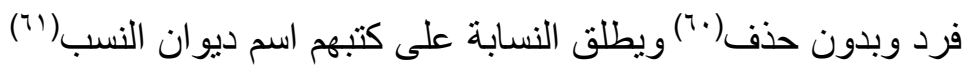
وكانت هذه الكتب تسـهل للنقبـاء عملهم في انسـاب السـادات في المدن و القصبات وكـان نقبـاء المـدن يطلعون نقباء المدن الاخرى لكي لا تحدث مشكلات للطالبين الذين يهاجرون من بلد إلى بلد لدى استلام رواتبهم

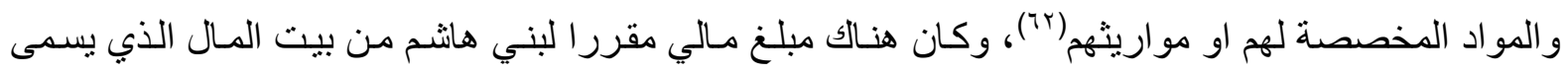
الراتب او الارزاق او سهم ذوي القربى او الرسوم الثهرية وبذات هذ الرسوم تدفع منذ عهد الدولة العباسية(זّ) عن طريق ديوان النقابة والنقباء حتى تطور في عهد السلاطين الايلخانيين الذي اصبح اهتمامهم بالعلويين بشكل كبير وخصصت لهم ايضا الامو ال الخاصة بهم خاصة في عهد السلطان غازان واخيه اليجاتو|(؟ج). كما كانت هناك أمو ال خاصة يقوم النقيب بتقسيمها وهو مبلـغ مـالي يدعى سـهم السـادات نتفع من قبل الثيعة للسيد وغير السبد إلى السـادات الايتام والمساكين و عابري السبيل وكان السـادة والمحتاجين يتجمعون حول النقيب ويتم توزيع المبـالغ تحت اشـر افه وكان النقيب ايضـا مسؤو لا عن المزارات والموقوفات والمر اقد وفي و المشـاهد المقدسة في جميع المدن فكانت النذور و الهـدايا التـي تصـل لهذه الامـاكن تجمع عند النقيب ويقوم 
بالتصرف فيها بحسب مستحقيها(70)، وظهر هذا الامر بصورة جلية عندما تولى السيد تـاج الدين النقابة فوض إليه السلطان اليجاتو المسؤولية على مرقد ذو الكفل الذي كان مسيطر على ادارتهه من قبل اليهود فجعل ادارتـه إلى السيد تاج الدين فضلا عن المر اقد الاخرى حيث يذكر ن السلطان اليجاتو اعطاه الاشر اف على الاوقاف في

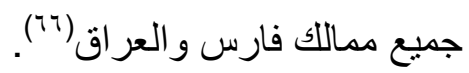

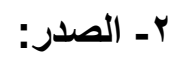

تعد وظيفة الصدر (†^) واحدة من الوظائف المهمـة في الدولة العربيـة الإسـلامية، فصـاحبها هو الحـاكم المسؤول عن الوحدة الإدارية فيشرف على القوات المسلحة و على حمايـة الأمن(^جا، فضـلا عن كل مـا يتعلق بالأمور الإدارية و المالية(79).

وجدت وظيفة الصدر في العصر العباسي الأخير وأخذت تطلق بدلاًعن لفظة الوالي، وكانت تسمية الصدر خلال هذه المدة تطلق على رئيس إحدى الدواوين المركزية، وفي الوقت نفسـه تطلق على رئيس الوحدة

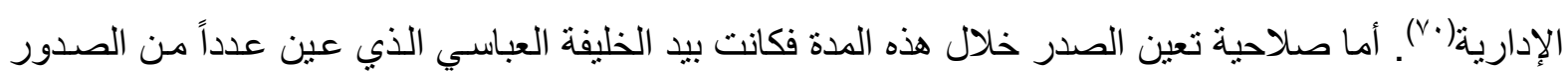

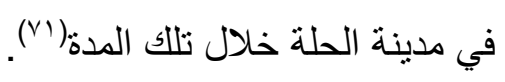

استمرت وظيفة الصدر في العصر المغولي، إلا أن هذه التسمية أطلقت على رئيس الوحدة الإداريـة

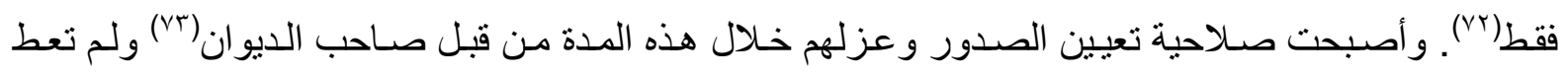

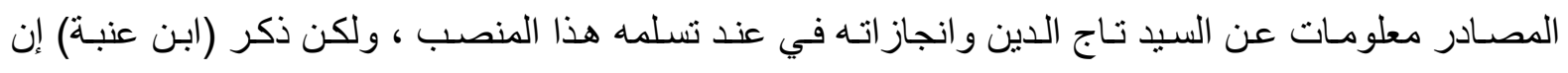
التاجيـة سميت باسم السبد تـاج الدين لو لايته عليها و اعماله فيها، وكان ذلك في سنة احدى عشرة وسبعمائة هجرية (V乏)

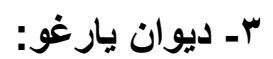

ويعني (ديوان المظالم والثكاوى)، وقد ذكر المؤرخ (شبنكارى تبrrه) إن "إن السيد الأبهري الاوي

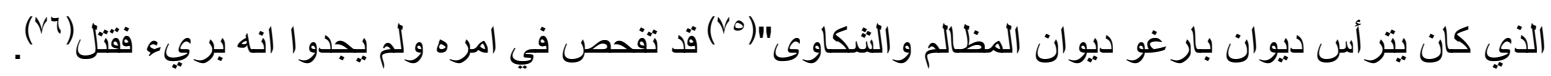
ولم تذكر المصادر سوى قضية واحدة قام السيد تاج الدين بحلها بين موظفي الديوان، حيث نشب نزاع بين موظفي و عمال الديو ان، وكل واحد منهم وجـه تهمـة صـرف أمو ال الديوان إلى الاخر، لكن الوزير سعد الساوجي طلب من السيد ناج الدين اجر اء الصلّح بينهم فاستدعى السيد تـاج الدين عمـال الديوان وصـالح بينهم و اقسموا على عدم تكرار النزاع(YYY)، و استخدمت هذه القضية ضد السيد تـاج الدين، وذكروا بأنه كان متعاونـاً معهم في سرفة أمو ال ديوان الممالك(V^) ولم نتمكن من فهم المعلومات التي جاءت في تاريخ وصـاف ضمن

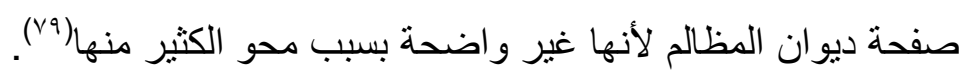

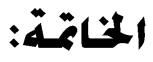

من خلال در استنا للنصوص التاريخيـة لمدة حكم غـازان، تبين ان السيد تـاج الدين كان شخصية لها اهميتها في الدولة الايلخانية، تمثل ذلك بتوليه مناصب سياسية واستشارية، بسبب ميل هذا السلطان الى رؤسـاء 
الثيعة الذي اطمأن اليهم سياسيا، بخلاف اهل السنه، لكن لم تذكر المصادر بصورة اوضح واوسع طبيعة عمله السياسي في عهذ غازان.

ظهر الدور السياسي للسيد تاج الدين في عهد السلطان اولجايتو بصورة بـارزة وجلية، بسبب تسلمه

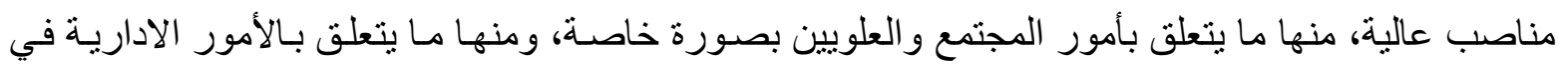
الدولة الايلخانية بصورة عامة.

• اظهرت الدراسـة ان التقارب الثيعي الايلخاني بين السيد تـاج الدين و السلطان اولجايتو وسبقه بـللك

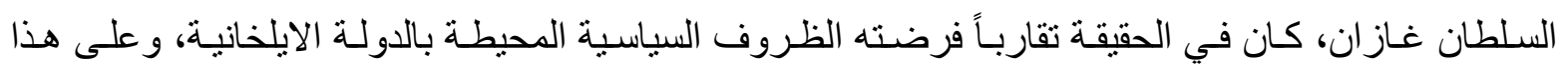
الأسـاس أستفاد من التقارب المغولي فضـلا عن استفادته مـن أجواء الحريـة المتوازنـة التـي اثـاعها المغول، وساعدته في تحقيق كثير من الإنجاز ات السياسية و العقائدية، التي كان يستعصي على العلمـاء الثيعة تحقيقها أيام العباسيين، حين كان تعاملهم مع الأمور السياسية يقوم على أساس التقية والعمل السري غير المعلن، الأمر

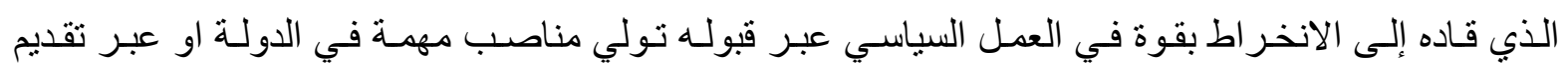
الاستشار ات التي كان يتداولها مع هؤلاء السلاطين من دون حرج عقائدي يذكر، وقد سـاعده هذا ان يصل الى لى البلاط المغولي. على الرغم مما تعرض له من مآسِ وظلم من قبل المعارضين لـه سواء من ابنـاء مذهبه او من بـاقي

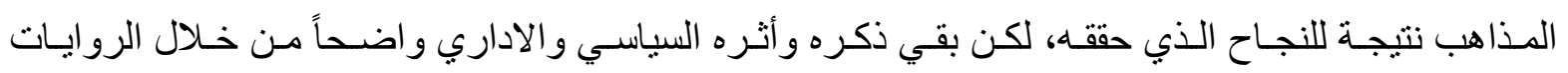
والاشتار ات القليلة التي وردت بخصوصه.

الهوامش والران

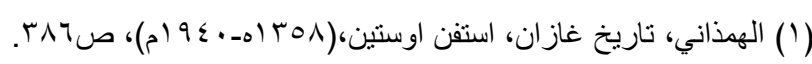
(Y) الشيرازي، تاريخ وصاف الحضرة، رقم ( 01 ) ) كتابخانه اية الله العظمى المرعشي، ص07؛

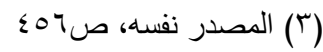
(§) تحدثنا عنه في الفصل الاول ضمن المبحث الاول (0) مر الحديث عن هذا الموضوع في الفصل الثالث ضمن المبحث الاول

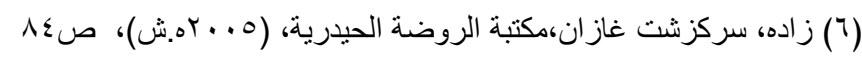

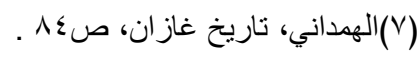

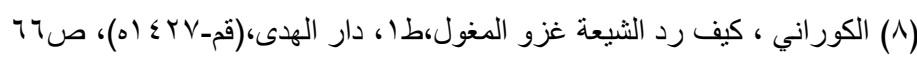
(9) مؤلف مجهول، الحو ادث الجامعة و التجارب النافعة في المائة السابعة و المنسوب لابن الفوطي، تحقيق:بشـار عو اد و الدكتور عمادعبد السـلام

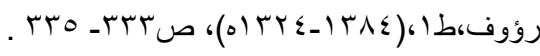

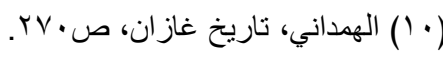

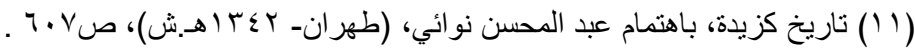




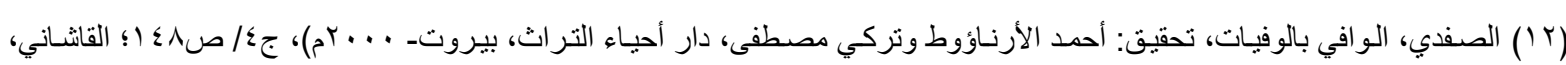

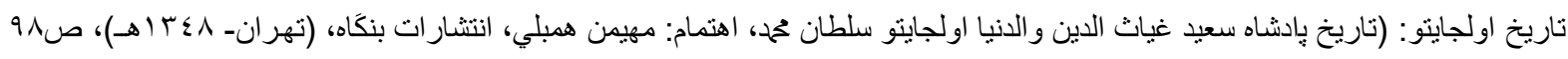

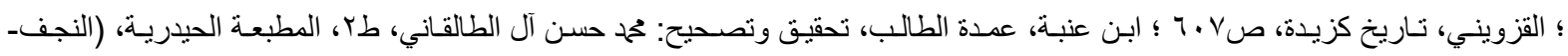

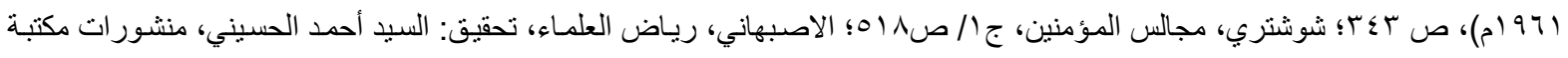

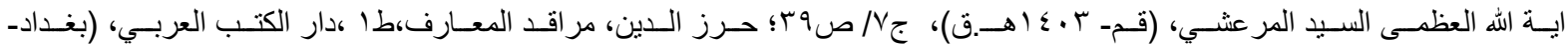

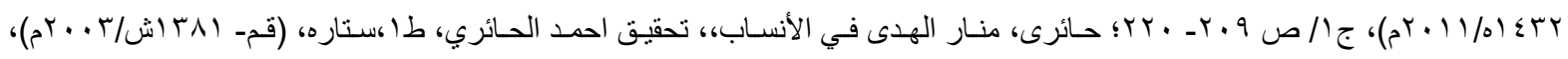

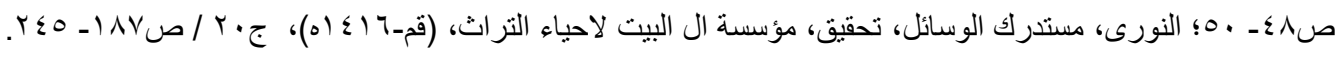

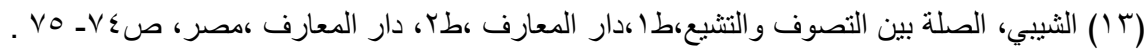

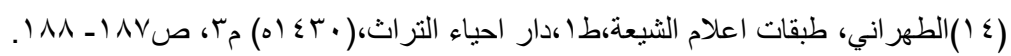

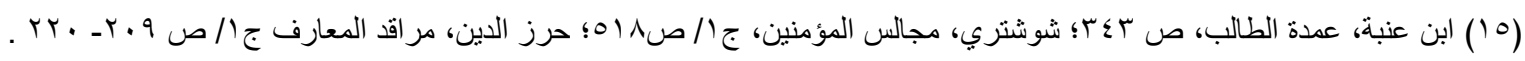
(7 (1 ) السلطان خدابنده و التشيع الامامي،ص 1'. . تاريخ وصاف، صץ ( IV)

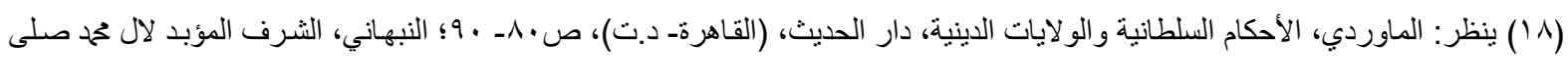

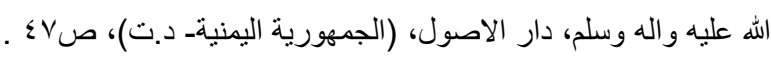

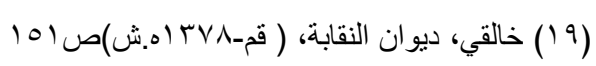

(†• الالبسة السوداء التي هي شعار الدولة العباسية وكان اهل الديوان و المسؤولين ملزمين بلبسها، وكانو ا يستلمون هذه الازيـاء على شكل هدايا من الدولة وفي اغلب الاحيان كانوا يرتدونها عند حضور هم بين يدي الخليفة، ومن بين الطالبيين الذين تولوا رئاسـة النقابـة في العهد العباسي

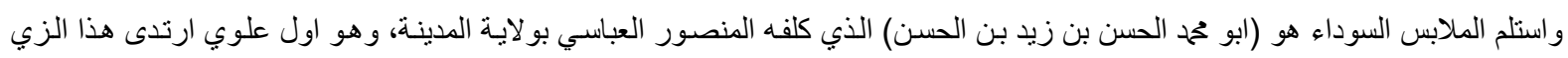

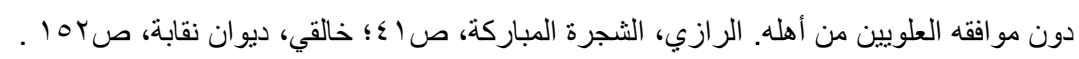
(Yl) (Yقيب نقباء الهاشمبين و هو اعلى المناصب في ديوان النقابة في العصر العباسي، وينصب الثخص فيه عندما يكون احد النقباء العباسبين مقبو لاً لدى الطالبين ايضا، وأول من تقلد هذا المنصب النقبب ابن طومار الأول، احمد بن عبد الصمد المشهور (ت ـ آهـ)، و عندما توفي اتفق

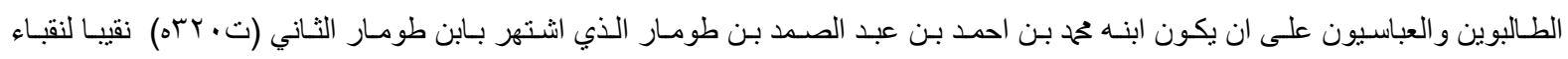

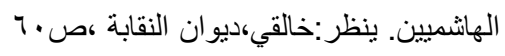

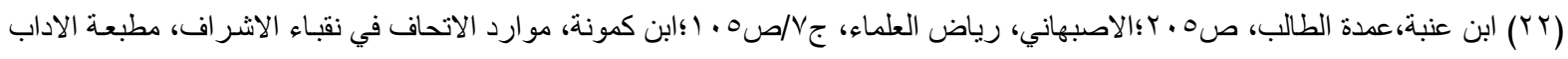

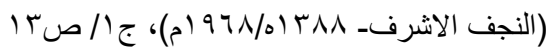

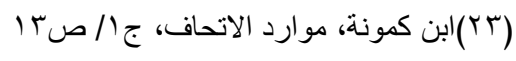

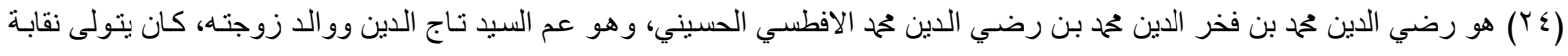
المشهد الغروي الثريف، وكان يطلق عليه ملك نقيب النقباء، توفي سنة (ء 77هـ). ينظر: ابن طاووس، فتح الابواب ، ، تحقيق حامد الخفاف

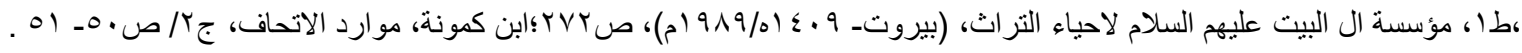
(Yo) هو موضوع بحثنا وسوف نتحدث عن نقابته في الصفحات اللاحقة من هذا المبحث.

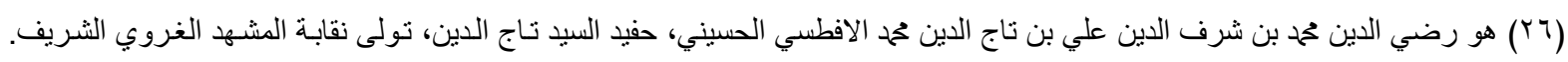

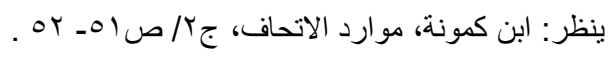


(TV) هو شمس الدين حسين بن رضي الدين ححمد شرف الدين علي بن تـاج الدين محم الافطسي الحسيني، ابن حفيد السيد تـاج الدين، تولى نقابـة المشهد الغروي الثريف. المصدر نفسه، جr/ صrه . (r^) شمس الدين حسين بن رضي الدين محمد بن شرف الدين علي بن تاج الدين محمد الاوي الحسيني، وهو أحد احفاد السيد تـاج الدين، تولى نقابـة المشهد الغروي الثريف بعد والده. ينظر: المصدر نفسه، جr/ صroه . (9 r هو جلال الدين علي بن شرف الدين المرتضى العلوي الحسيني الاوي، كان نقيبا بالمشهد العلوي الثريف، وصف باوصـاف عدة منها: ملك السادات و النقباء، وهو من نقباء القرن السابع الهجري. ينظر : ابن كمونة، موارد الاتحاف، صكاه .

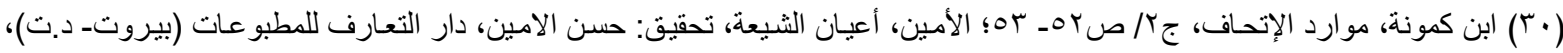
. 1199

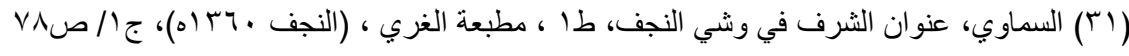

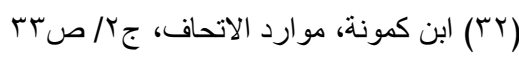
r.

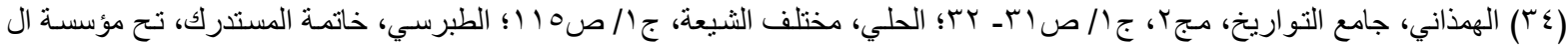

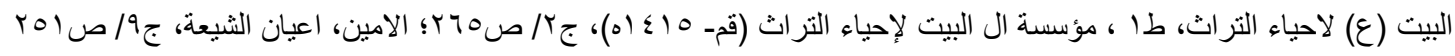

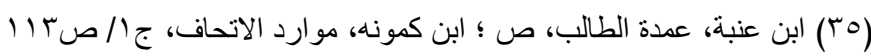

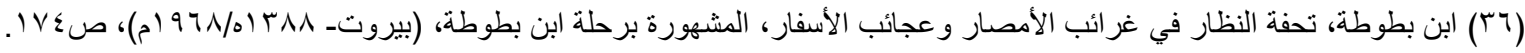

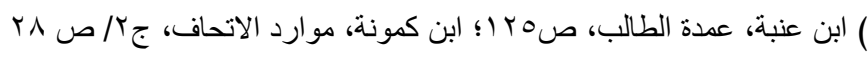

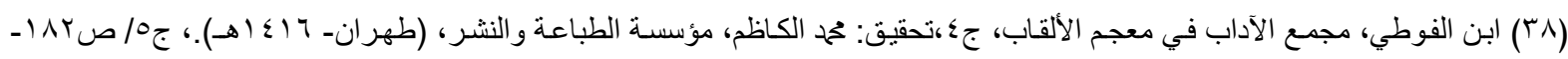

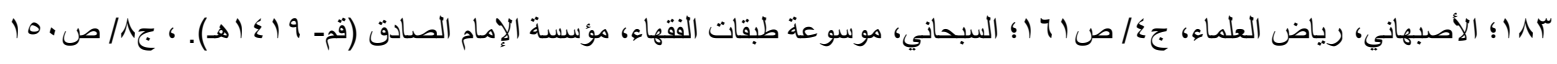
(9 (؟) نولى النقابة الطاهرية بالعر اق وكان جو اداً كريماً جليلاً وجيهاً، ولما توفى نقل جثمانه من الحلة إلى النجف. ينظر : كركوش، تاريخ الحلة،

$$
\begin{aligned}
& \text { ص. } 9
\end{aligned}
$$

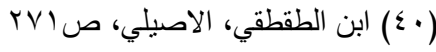

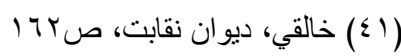

(ץ乏) ابن تغري بردي، النجوم الزاهرة في ملوك مصر و القاهرة، دار الكتب، (القاهرة- د.ت)، جه/ ص9 | |؛ ابن الجوزي، المنتظم في تاريخ الأمم و الملوك، تحقيق: ححمد عبد القادر عطا ومصطفى عبد القادر عطا، دار الكتب العلمية (بيروت- ب99 (م)، جV/ صبrه

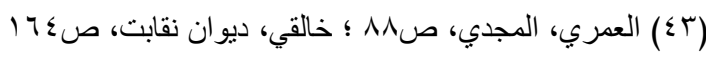

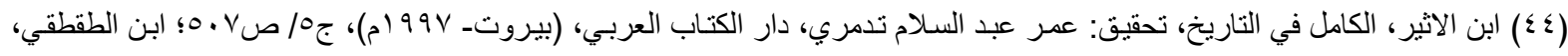

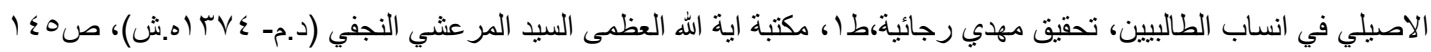

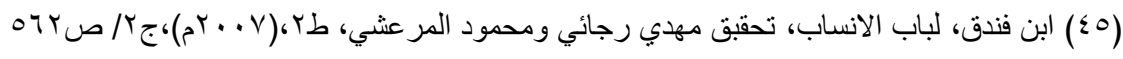

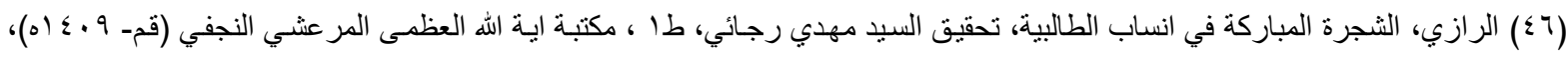




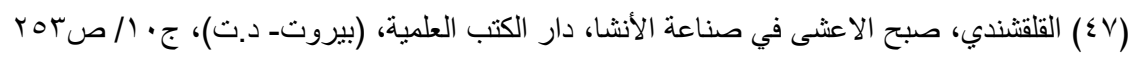

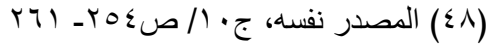

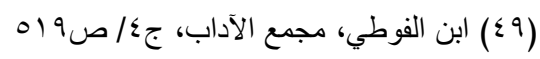

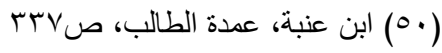

(1) (1) ابن الطقطقي، الاصيلي، صVIr)

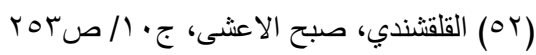

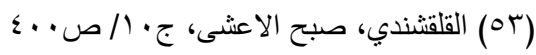

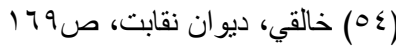

(00)مؤلف مجهول ، الحوادث الجامعة، صمץ

(بان

179 1 19 ) خالقي، ديوان نقابت

(ON) القلقندي، صبح الاعشى، ج• / / ص آr

(09) تحدثنا عنه في الفصل الاول ضمن المبحث الثاني

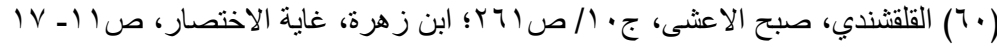

197 ابن عنبة، عمدة الطالب، ص190 197

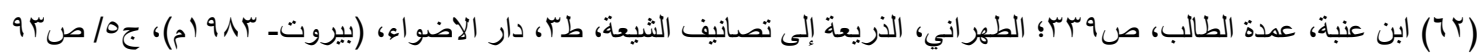

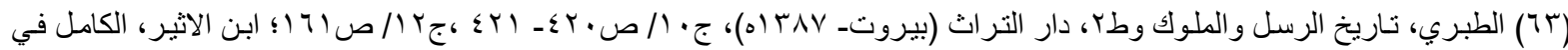

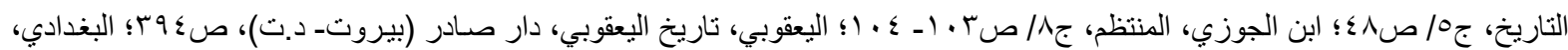

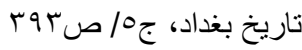
( (؟) تحدثنا عن هذا الموضوع في الفصل لثالث ضمن المبحث الاول

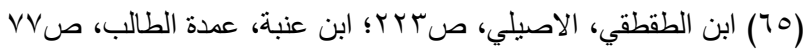

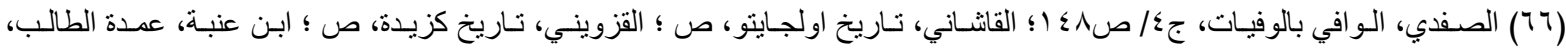

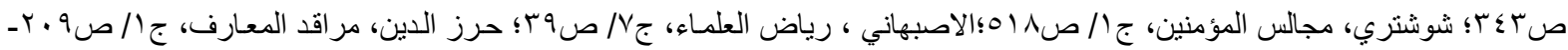

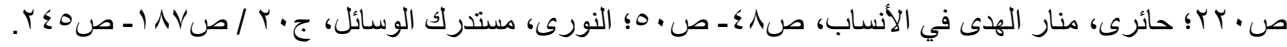

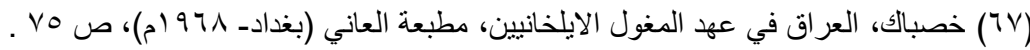

(1) إن هذه الوظيفة في وقتنا الحاضر توازي وظيفة المحافظ أو المنصرف أو المدير العام بـاختلاف اختصـاص الصدرية وصـلاحيتها ـ ينظر: آل ياسين، در اسة في التاريخ الاجتماعي لصدور العر اق في عهد التسلط المغولي، مجلة كلية المعلمين، الجامعة المستتصرية، العدد(ب ())، بغداد ، 
( • ( إن الساعي، الجامع المختصر المختصر في عنوان التواريخ وعيون السير،جو، تحقيق: د.مصطفى جو اد، المطبعة السريانية الكانوليكية

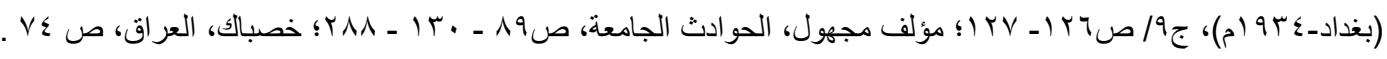

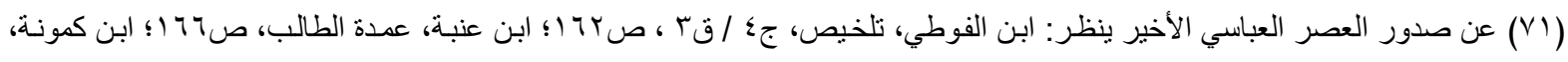

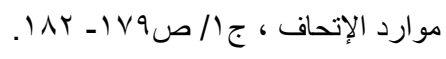
V

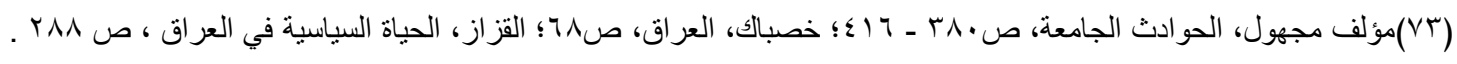
(ابن عنبة، عمدة الطالب، صب (V )

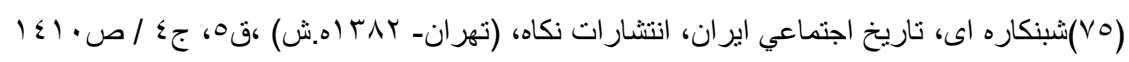
شبنكاره اى، مجمع الانساب،(تهران-rT)

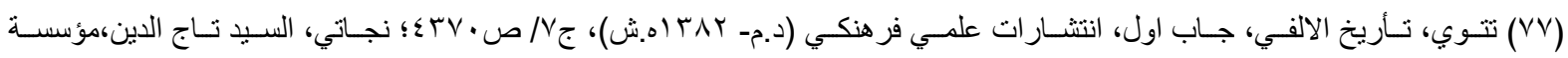

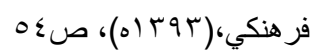
(V^) (الثيرازي، تاريخ وصاف، ص (1) 